\title{
Global Uncertainty Analysis for RRKM/Master Equation Based Kinetic Predictions: A Case Study of Ethanol Decomposition
}

\author{
Lili Xing, ${ }^{a,{ }^{+}}$Shuang Li,${ }^{a, b+}$ Zhaohui Wang, ${ }^{a}$ Bin Yang, ${ }^{b}$ Stephen J. Klippenstein, ${ }^{c}$ Feng Zhang ${ }^{a, *}$
}

\begin{abstract}
${ }^{a}$ National Synchrotron Radiation Laboratory, University of Science and Technology of China, Hefei, Anhui 230029, P. R. China

${ }^{b}$ Center for Combustion Energy and Department of Thermal Engineering, Tsinghua University, Beijing, 100084, P. R. China
\end{abstract}

${ }^{c}$ Chemical Sciences and Engineering Division, Argonne National Laboratory, Argonne, IL 60439, USA

\begin{abstract}
A precise understanding of the accuracy of reaction rate constants, whether determined experimentally or theoretically, is of considerable importance to kinetic modelers. While the uncertainties of experimentally measured rate constants are commonly provided, the "error bars" of computed (temperature- and pressure-dependent) rate constants are rarely evaluated rigorously. In this work, global uncertainty and sensitivity analysis is applied to the propagation of the uncertainties in the input parameters (e.g. barrier heights, frequencies and collisional energy transfer parameters et al.) to those in the rate constants computed by the RRKM/master equation method for the decomposition of ethanol. This case study provides a systematic exploration of the effect of temperature and pressure on the parametric uncertainties in RRKM/master equation calculations for a prototypical single-well multiple-channel dissociation. In the high pressure limit, the uncertainties in the theoretical predictions are controlled by the uncertainties in the input parameters involved in the transition state theory calculations, with the most important ones being those describing the energetics of the decomposition. At lower pressures, where fall-off is important, the uncertainties in the collisional energy transfer parameters play a significant role, particularly for the higher energy of
\end{abstract}

\footnotetext{
*Corresponding author: feng2011@ustc.edu.cn Tel: +86-55163607923
} 
the two channels. Remarkably, the competition between dissociation and collisional excitation leads to uncertainties of more than a factor of 100 in the predictions for the higher energy channel. These large uncertainties are related to the need for large-scale single-collision-induced transitions in energy in order to produce the higher energy products in the low pressure limit. The present study illustrates the value of detailed qualitative and quantitative studies of the uncertainties in theoretical kinetics predictions.

Keywords: transition state theory, RRKM/master equation method, uncertainty analysis, sensitivity analysis, collisional energy transfer model 


\section{Introduction}

Unimolecular decompositions are commonly the first step in the conversion of a fuel in combustion systems. Correspondingly, the accurate determination of rate coefficients for unimolecular reactions has attracted a great deal of attention from combustion kinetics researchers [1-9]. The RRKM/master equation (ME) method is the preferred approach for computing the temperature- and pressure-dependent rate coefficients for unimolecular reactions [10-13]. The accuracy of RRKM/ME computed rate constants is highly dependent on the uncertainty of input parameters such as energy barriers, vibrational frequencies, collisional energy transfer parameters, etc. Uncertainty estimates for such theoretical predictions are of crucial importance to combustion modelers because they propagate into uncertainties in the predictions for global observables such as the ignition delay and flame speed. On the other hand, the uncertainties in such global observables provide an indication of the reliability of the model and are used to motivate further research into the reactions with the greatest contribution to the global uncertainties.

The uncertainties of computed rate constants have rarely been evaluated rigorously. Instead, most uncertainty estimates for theoretical kinetics predictions are obtained from experience-based expertise on limited parameters such as the energy barriers [14-16]. The uncertainty in the high pressure limit (HPL) rate constants are relatively easy to evaluate through transition state theory (TST), to the uncertainty in computed energies and frequencies, etc. [17]. However, when considering the role of the collisional excitation process and the corresponding dependence on pressure, the deduction of rate constants (through RRKM/ME theory) becomes much more complicated and involves strong couplings of the various input parameters. In this instance, it is difficult to predict analytically the propagation of the uncertainties from the input parameters to the computed phenomenological rate constants. 
Recently, the random sampling high dimensional model representation (RS-HDMR) approach [18-28] was employed in a global uncertainty and sensitivity analysis of RRKM/ME rate constants for the oxidation of the n-propyl radical by Goldsmith et al. [29]. The uncertainties in the fundamental theoretical parameters (such as the reactant and transition state energies, energy transfer parameters, etc.) were propagated through to the determination of the distribution and sensitivities of the phenomenological rate constants. Input parameters with high first- and second- order sensitivities were presented for various reaction channels; the uncertainties of the computed rate constants were qualitatively revealed by their normalized frequency distributions computed from random sampling input parameters [29].

Enlightened by this prior work, we have employed the same RS-HDMR method to explore the temperature and pressure dependence of the uncertainties in RRKM/ME based kinetic predictions for the thermal decomposition of ethanol. This system, which is of considerable interest to combustion modelers, represents a prototypical single-well multi-channel decomposition, with both tight and loose transition states playing key roles. Prior studies have shown that the thermal decomposition of ethanol is dominated by three reaction channels, i.e., $\mathrm{H}_{2} \mathrm{O}$ elimination via a tight transition state with large reverse barriers and "barrierless" $\mathrm{C}-\mathrm{C}$ and $\mathrm{C}-\mathrm{O}$ bond fissions, where there is no reverse barrier $[14,15,30]$

$\mathrm{CH}_{3} \mathrm{CH}_{2} \mathrm{OH} \rightarrow \mathrm{C}_{2} \mathrm{H}_{4}+\mathrm{H}_{2} \mathrm{O}$

$\mathrm{CH}_{3} \mathrm{CH}_{2} \mathrm{OH} \rightarrow \mathrm{CH}_{3}+\mathrm{CH}_{2} \mathrm{OH}$

$\mathrm{CH}_{3} \mathrm{CH}_{2} \mathrm{OH} \rightarrow \mathrm{C}_{2} \mathrm{H}_{5}+\mathrm{OH}$

Notably, the barrier for (R2) lies significantly above the threshold for (R1), while that for (R3) lies even higher. Furthermore, (R1) has a relatively low entropy (or tight) TS, while (R2) has a relatively 
high entropy (or loose) TS. As a result, there is an interesting competition between (R1) and (R2), with (R1) of dominant importance at low temperature and/or low pressure, and (R2) increasing in importance at higher temperatures and pressures. The result of this competition is strongly connected to the collisional excitation process. The simplicity of this reaction system allows us to directly explore the effect of this competition on the uncertainties in the predictions via the implementation of an extensive global uncertainty analysis for a variety of temperatures and pressures. Furthermore, the barrierless nature of (R2), leads to an interesting exploration of uncertainties arising from variational transition state theory (VTST) calculations.

Numerous experimental and theoretical studies of ethanol decomposition have been presented due to its significant role as a biofuel [14, 15, 30-37]. Sivaramakrishnan et al. [15] computed the rate constants for ethanol decomposition by the RRKM/ME method, while treating the barrierless C-C bond fission with the sophisticated variable reaction coordinate transition state theory (VRC-TST) $[38,39]$. The barrier heights and collisional parameters in their analysis were optimized against shock tube measurements. The authors predicted a greater uncertainty in the rate constants for R2 and R3 than for R1, given the difficulty of measurements for the low branching channel and the strong sensitivity of the corresponding theoretical predictions to the details of the energy transfer process (depending on both the energy transfer parameters and the energy gap between the barriers of competing channels). Very recently, Kiecherer et al. [14] studied ethanol pyrolysis with shock-tube/time-of-flight mass spectrometry experiments and computed the rate coefficients by the master equation method with a stepladder energy transfer model [40].

These previous studies indicate that the uncertainty in the computed rate constants for different reaction channels exhibits different behavior, which also depends on temperature and pressure. 
Why? And how? With the aid of sensitivity and uncertainty analysis for various temperatures and pressures, we will investigate these issues both qualitatively and quantitatively in this work.

\section{Theoretical methods}

\subsection{Potential energy surfaces}

Previous studies have shown that the $\mathrm{C}-\mathrm{O}$ fission (R3) makes at most a minor contribution $(<5 \%)$ under combustion conditions $[14,15,30,33]$. Thus, to reduce the computational cost of the global uncertainty analysis, only channels R1 and R2 were studied in this work. For these channels, stationary point optimization and frequency analyses were performed with the B3LYP/6-311++G(d,p) method, just as in the reference 15. Single point energies (SPEs) were computed by Sivaramakrishnan et al. with the QCISD(T) method employing a complete basis set (CBS) extrapolation based on calculations for the cc-pVTZ and cc-pVQZ basis sets [15, 41]. The dissociation curve for the barrierless channel R2 was constructed for a grid of C-C separations with a grid spacing of $0.1 \AA$ using the CASPT2(2e,2o)/cc-pVDZ method. Then the CASPT2(2e,2o)/cc-pVDZ energy for each point along the dissociation curve was scaled by the ratio of the QCISD(T)/CBS [15] and CASPT2(2e,2o)/cc-pVDZ calculated dissociation energies. The harmonic frequencies along the $\mathrm{C}-\mathrm{C}$ fission curve were also obtained with the CASPT2(2e,2o)/cc-pVDZ method. The active orbitals correlate with the methyl and hydroxymethyl radical orbitals. All the quantum chemical calculations were carried out with either the Gaussian 09 [42] or MOLPRO program packages [43].

\subsection{Kinetic theories}


The C-C bond dissociation channel was studied with the canonical variational transition state theory (CVT[44]). Within CVT, for each temperature, the variational transition state is specified as the geometry giving the minimum in the HPL rate constant, $\mathrm{k}_{\mathrm{HPL}}(\mathrm{T})$. The master equation employs RRKM theory calculated microcanonical rate constants for these variational transition states, as well as for the tight TS of the $\mathrm{H}_{2} \mathrm{O}$ elimination channel. The master equation simulations then couple these RRKM evaluations with models for the collision induced dissociation process in the determination of phenomenological rate constants for $\mathrm{R} 1$ and $\mathrm{R} 2$ at various temperatures and pressures. Eckart tunneling corrections [45] are included in the RRKM calculations. For both the minimum and the TS structures, the low frequency vibrational modes corresponding to internal rotations of the $-\mathrm{CH}_{3}$ group were treated as hindered rotors, where the hindrance potential is fitted with a symmetric Fourier cosine function.

$$
\mathrm{V}(\theta)=\frac{V_{0}}{2}(1-\cos 3 \theta)
$$

The barrier height $V_{0}$ was calculated at the level of $M 06-2 X / 6-311+G(3 d f, 2 p)$. All other modes were treated with rigid-rotor harmonic-oscillator (RRHO) assumptions.

For the collisional model used in the master equation simulation, the interaction between the reactant and the bath gas Ar was modeled by the Lennard-Jones (L-J) potential [46]. The L-J parameters were chosen as $\sigma=3.465 \AA, \varepsilon=113.5 \mathrm{~K}$ for $\operatorname{Ar}[47-49]$; and $\sigma=4.317 \AA, \varepsilon=450.2 \mathrm{~K}$ for ethanol [33]. The collisional energy transfer function was represented by a single-parameter temperature dependent exponential down model with $<\Delta \mathrm{E}>_{\text {down }}=125(\mathrm{~T} / 298)^{0.85} \mathrm{~cm}^{-1}$, which has proven to be an effective model in previous studies [15]. Partition functions were evaluated at the E-resolved level and the energy grain spacing was set to $40 \mathrm{~cm}^{-1}$, which was found to provide converged results $[46,50]$. All the kinetic calculations were performed using the MESMER program $[50,51]$. Jasper et al. explored the effect of a variety of bath gases to the accuracy of conventional 
energy transfer models used in ME simulations [52-55]. Their findings suggest that the present temperature dependent representation for $\langle\Delta \mathrm{E}\rangle_{\text {down }}$ is reasonable. The uncertainty introduced by the collisional energy transfer model studied in this work only reflects the parameterized uncertainty within such a simple collisional energy transfer model.

The ethanol decomposition has been well studied at high levels of theory $[14,15]$. The VRC-TST method employed by Sivaramakrishnan et al. generally provides a more accurate description for barrierless channels than the CVT algorithm used in this work. However, the aim of this work is not to provide the most accurate rate constants, but instead to explore the dependence of the uncertainty on key theoretical parameters. The CVT analysis employed here facilitates this global uncertainty and sensitivity analysis, providing simple parameters for variation in the exploration of the uncertainties. Notably, this uncertainty analysis requires millions of RRKM/ME calculations in order to provide an appropriate sampling over the various input parameters for a range of temperatures and pressures.

\subsection{Uncertainty and sensitivity analysis}

Global uncertainty and sensitivity analysis was used to study the propagation of uncertainties in fundamental input parameters to those in the predicted temperature and pressure dependent rate constants. The first- and second-order sensitivity coefficients for each reaction were calculated using the RS-HDMR method [20], which maps the relationship between the input variables and output variables using a set of random samples based on the assumption that high order correlations between the input variables are negligibly small [19]. For most well-defined physical and chemical systems, an RS-HDMR expansion up to second order provides a satisfactory approximation to the original model [21]. The truncated HDMR can be expressed as: 
$f(\mathrm{x})=f_{0}+\sum_{i=1}^{n} f_{i}\left(x_{i}\right)+\sum_{1 \leq i<j} f_{i j}\left(x_{i}, x_{j}\right)$

Here $n$ is the number of input variables, $f_{0}$ represents the mean value of the output, $f_{i}\left(x_{i}\right)$ represents the independent effect of the $x_{i}$ upon the output, $f_{i j}\left(x_{i}, x_{j}\right)$ represents the cooperative effect of the variables $x_{i}$ and $x_{j}$ upon the output. Li et al. provided a method to construct the RS-HDMR expansion using orthonormal polynomials, then E1 can be written as [22]:

$f(\mathbf{x})=f_{0}+\sum_{i=1}^{n} \sum_{r=1}^{t} \alpha_{r}^{i} \varphi_{r}\left(x_{i}\right)+\sum_{1 \leq i<j<n} \sum_{p=1}^{t 1} \sum_{q=1}^{t 2} \beta_{p q}^{i j} \varphi_{p}\left(x_{i}\right) \varphi_{q}\left(x_{j}\right)$

where $\varphi$ is orthonormal polynomial, and $\mathrm{t}, \mathrm{t} 1, \mathrm{t} 2$ are the order of the orthonormal polynomials. The coefficients $\alpha_{r}^{i}$ and $\beta_{p q}^{i j}$ are obtained through a minimization process and Monte Carlo integration. After that, the partial variances are readily estimated:

$D_{i}=\sum_{r=1}^{t}\left(\alpha_{r}^{i}\right)^{2}$

$D_{i j}=\sum_{p=1}^{t 1} \sum_{q=1}^{t 2}\left(\beta_{p q}^{i j}\right)^{2}$

where $D_{i}$ is the $i$ th first-order variance, and $D_{i j}$ is the second-order variance between the $i$ th and $j$ th parameters, and the total variance is estimated as $\mathrm{D}=\frac{1}{n} \sum_{m=1}^{n} f^{2}\left(\boldsymbol{x}_{m}\right)-f_{0}{ }^{2}$. The sensitivity indices can be calculated according to the variances, $S_{i}=\frac{D_{i}}{D}, S_{i j}=\frac{D_{i j}}{D}$, where $S_{i}$ indicates the independent effect of $x_{i}$ on the variance of $f(\mathbf{x})$, and $S_{i j}$ represents the interaction effect of $x_{i}$ and $x_{j}$ on the output.

In this work, sensitivity and uncertainty analyses were performed for the natural logarithm of the rate constant $-\ln k$. It is commonly assumed that the uncertainty of an always positive parameter, such as the rate constant, has a lognormal distribution [56-58]. For such a variable, it's advisable to take its logarithm rather than the absolute value as the target for the uncertainty analysis. The uncertainty factor $U$ can be computed from the standard deviation $\sigma$ of $\ln k$ coupled with a selected confidence interval for the rate constant, which was chosen as 0.95 [56] in this work, i.e.

$\mathrm{P}\left(\frac{\mathrm{k}_{\text {nominal }}}{U} \leq k \leq \mathrm{k}_{\text {nominal }} * U\right)=0.95$

Then $\ln k$ can be specified as $\ln k \sim \mathrm{N}\left(\ln k_{\text {nominal }}, \sigma^{2}\right)$ with 
$\ln U=1.96 \sigma$

Thus, according to (E5) and (E6), the uncertainty factor $U$ of the RRKM/ME predicted rate constants can be deduced from the standard deviation of $\ln k$.

Twenty two input parameters (including energies of reactants and transition states, collisional energy transfer parameters, low frequencies, imaginary frequencies, hindered rotor barrier heights) with specific uncertainties were chosen as the variables for the uncertainty and sensitivity analysis, as listed in Table 1. The uncertainties for these input parameters were chosen according to expert estimation for the current theoretical levels. The calculations were performed for temperatures ranging from $800-2000 \mathrm{~K}$ with the grid of $100 \mathrm{~K}$ and for five pressures of $0.001,0.01,0.1,1$, and 10 atm. For each (T, P) pair, 20000 samples were randomly and uniformly generated in the parameter space and the corresponding rate constants were then calculated. The results were checked for convergence with respect to this sample number. The software GUI-HDMR [26] was used to perform this sensitivity and uncertainty analysis for reactions R1 and R2 based on the selected input parameters.

\section{Results and discussion}

Table 2 compares the stationary point energies including the zero-point energy (ZPE) correction for R1 and R2 computed by various methods as reported in literatures. A schematic potential energy profile is also provided in the Supplemental Material (cf. Fig. S1). The QCISD(T)/CBS and CCSD(T)-F12/def2-QZVPP results should be nearly converged with respect to the basis set for both the TS1 energy and the dissociation energies. Nevertheless, the uncertainties are still estimated as $\pm 1.0 \mathrm{kcal} / \mathrm{mol}$ for the energy of minimum structures and $\pm 2.0 \mathrm{kcal} / \mathrm{mol}$ for the TS energies due to the uncertain contributions from other neglected terms such as higher order excitations, core-valence corrections, and anharmonic zero-point energies. 
The energy and uncertainty in the TS2 energy doesn't necessarily correlate directly with that of the corresponding dissociation energy; instead, it is also strongly dependent on the dissociation curve and the details of the VTST analysis. Figure 1 illustrates the C-C bond dissociation curves calculated at the CASPT2(2e,2o)/cc-pVDZ level and scaled to the QCISD(T)/CBS dissociation energy. The variation of the TS location with temperature is also shown in Fig. 1. The barrier height of the canonically optimized TS decreases with increasing temperature, which has a significant impact on the uncertainty analysis due to its effect on the competition between R1 and R2. It will be discussed in more detail below.

The computed RRKM/ME rate constants based on this CVT strategy for R2 are shown in Fig. S2 in the Supplemental Material, together with those based on VRC-TST [15] for comparison. The largest discrepancy between our CVT results and the VRC-TST [15] results is a factor of 3 over the studied temperature and pressure range. As was stated before, the VRC-TST should provide more accurate rate constants than the CVT used in this work, however, the CVT method was chosen here due to its convenience and effectiveness for the uncertainty analysis. The fact that the characteristics of the canonical TS employed in CVT only change with temperature facilitates the uncertainty analysis. The key conclusions obtained from the uncertainty analysis are independent of whether the "transition state" for the barrierless reaction is analyzed by CVT or by VRC-TST.

\subsection{Sensitivity analysis}

The sensitivity is the factor ranking the impact of the uncertainties in the input parameters on the computed rate constants. The main first- and second-order sensitivities at $1500 \mathrm{~K}$ and five pressures $(0.001,0.01,0.1,1$, and $10 \mathrm{~atm})$ for R1 and R2 are listed in Table 3. The second-order sensitivities are very small for these reactions under various conditions, and a similar phenomenon was observed 
by Goldsmith et al. for the $n$-propyl oxidation system [29]. Hence, hereafter, we will only discuss the first-order impact and its variation with temperature and pressure. Table 3 shows that the first nine parameters contribute more than $95 \%$ of the (first order) sensitivities for both $\mathrm{R} 1$ and $\mathrm{R} 2$ under all conditions listed. These parameters include the prefactor and T-exponent of $\langle\Delta \mathrm{E}\rangle_{\text {down }}$, energies for the transition states and reactant, the L-J parameter $\sigma$ for $\mathrm{C}_{2} \mathrm{H}_{5} \mathrm{OH}$ and $\mathrm{Ar}$, and the imaginary frequency of TS1. The $\langle\Delta \mathrm{E}\rangle_{\text {down }}$ prefactor has much larger sensitivity than the T-exponent due to the different uncertainties assumed for these two parameters (cf. Table 1).

Figures 2 and 3 show the variation of the sensitivities with temperature and pressure for R1 and $\mathrm{R} 2$, respectively. Large sensitivities to the energies of the reactant $\left(\mathrm{C}_{2} \mathrm{H}_{5} \mathrm{OH}\right)$ and transition states are observed for both reactions. The sensitivity to the TS energy is larger than that to the $\mathrm{C}_{2} \mathrm{H}_{5} \mathrm{OH}$ energy, since we defined the TS energy uncertainty as $2.0 \mathrm{kcal} / \mathrm{mol}$, which is twice as large as for the $\mathrm{C}_{2} \mathrm{H}_{5} \mathrm{OH}$ energy. Besides these energy parameters, the $<\Delta \mathrm{E}>_{\text {down }}$ parameter $\left[(125 \pm 50 \%)(\mathrm{T} / 298)^{(0.85 \pm 0.15)} \mathrm{cm}^{-1}\right]$ is also seen to have a great influence on both $\mathrm{k}_{1}$ and $\mathrm{k}_{2}$ at the studied temperatures and pressures. The large uncertainty of the pre-factor of $\left\langle\Delta \mathrm{E}>_{\text {down }}( \pm 50 \%)\right.$ contributes to the significance of its sensitivity factor. The previous study by Goldsmith et al. also found that $\left\langle\Delta \mathrm{E}>_{\text {down }}\right.$ was a major uncertainty source for the more complicated n-propyl oxidation reaction system [29]. It would certainly be valuable if the energy transfer parameters in pressure dependent kinetic studies could be constrained to a smaller range. Very recently, Jasper et al. suggested that trajectory-based determinations of moments of the E, J-resolved collisional transfer rates coupled with the two-dimensional master equation could provide more accurate treatments of the effects of the collisional transition process [53]. The other parameters, such as the imaginary frequencies and L-J parameters play minor roles, as can be seen from Table 3. The slight irregularities in the sensitivity curves shown in Fig. 3 can be explained by the steps in the location of 
the canonically determined variational barrier, as shown in Fig. 1. Smoother sensitivity curves could be obtained with the use of a finer grid in the variational TST calculations.

The effect of the collisional energy transfer parameters $\left(<\Delta \mathrm{E}>_{\text {down }}, \sigma\right)$ becomes more significant with increasing temperature and decreasing pressure. This finding can be attributed to the fact that collisional energy transfer and microcanonical dissociation rates become more competitive as the temperature increases and/or the pressure decreases. Interestingly, for $\mathrm{k}_{2}$, in addition to the expected large sensitivity to $\left\langle\Delta \mathrm{E}>_{\text {down }}\right.$ and the TS2 energy, there is also a strong sensitivity to the TS1 energy, while the sensitivity to the reactant energy is only of significance at high pressures. These findings are an indication that the population of states at energies near TS2 is greatly influenced by the rates for the dominant channel R1, especially at low pressure. In essence, the competition between dissociation to R1 and collisional excitation to energies above TS2 yields strong sensitivities for $\mathrm{k}_{2}$ on both dissociation processes in addition to the excitation process. A more detailed discussion of this competition between dissociation and excitation will be provided in Section 3.2.

\subsection{Uncertainty analysis}

As mentioned above, it is common to assume that measured (or computed) rate constants have a lognormal distribution, which is the reason for choosing $\ln k$ as the target of the uncertainty analysis in this work. Figure 4 shows the normalized frequency distribution for $\mathrm{k}_{2}$ and $\ln k_{2}$ at $1500 \mathrm{~K}$ and $0.01 \mathrm{~atm}$ as determined by random sampling of the input parameters. These plots show an approximate lognormal distribution of the rate constants, validating the choice of $\ln k$ rather than $k$ as the target for the uncertainty analysis.

Figure 5 shows the normalized frequency distribution of $\log _{10}\left(\mathrm{k} / \mathrm{k}_{\text {nominal }}\right)$ at $1500 \mathrm{~K}$ and either $0.01 \mathrm{~atm}$ or the high pressure limit for both $\mathrm{k}_{1}$ and $\mathrm{k}_{2}$. The width of these frequency distributions indicates the overall uncertainty of the rate constants. Comparing the frequency distributions for $\mathrm{k}_{1}$ 
and $\mathrm{k}_{2}$, one sees that $\mathrm{k}_{2}$ has much higher uncertainty than $\mathrm{k}_{1}$ at 0.01 atm, while the uncertainties of $\mathrm{k}_{1}$ and $\mathrm{k}_{2}$ are very similar in the high pressure limit. These two contrasting cases will be analyzed separately below.

\subsubsection{High pressure limit}

The HPL rate constant is computed via transition state theory as:

$k_{H P L}(T)=\frac{k_{B} T}{h} \times \frac{Q^{\neq}}{Q_{R}} \times \exp \left(-\frac{\epsilon^{*}}{R T}\right)$

where $k_{B}$ is Boltzmann's constant, $h$ is Planck's constant, $\in^{*}$ is the barrier height, and $Q^{\neq}, Q_{R}$ represent the partition functions of the transition state and reactant, respectively. The logarithmic form of $\mathrm{k}$ can be written as,

$\ln k_{H P L}(T)=\ln \frac{k_{B} T}{h}+\ln \left(Q^{\neq}\right)-\ln \left(Q_{R}\right)-\epsilon^{*} / R T$

From (E8), the contributions to the uncertainty of $\ln \left(k_{\mathrm{HPL}}\right)$ originating from the energy and from the partition functions can readily be decoupled. The variance in $\ln \left(k_{\mathrm{HPL}}\right)$ arising from the energy parameters can be written as,

$D_{E}\left[\ln k_{H P L}(T)\right]=(1 / R T)^{2} D\left(\epsilon^{*}\right)$

Here $D\left(\in^{*}\right)=D\left(E_{T S}-E_{R}\right)$. The energies of the TS and of the reactant are assumed to follow uniform distributions in this work, for which the probability distribution function is,

$f(x)=\frac{1}{2 C} \quad\left(x_{0}-C \leq x \leq x_{0}+C\right)$

The variance of a uniform distribution is $(2 C)^{2} / 12$. With the uniform distribution assumption, the standard variance of $\ln k_{\mathrm{HPL}}(\mathrm{T})$ arising from only the energy parameters can be derived as:

$\sigma_{E}\left[\ln k_{H P L}(T)\right]=\frac{\sqrt{\left(\Delta E_{R}\right)^{2} / 12+\left(\Delta E_{T S}\right)^{2} / 12}}{R T}$

Here $\Delta E_{R}$ and $\Delta E_{T S}$ denote the uncertainty range for the energies of reactant and TS, respectively. Combining (E11) with (E6), the logarithm of the uncertainty factor due to the energy parameters becomes 
$\ln U_{E}=1.96 \sigma=1.96 \frac{\sqrt{\left(\Delta E_{R}\right)^{2} / 12+\left(\Delta E_{T S}\right)^{2} / 12}}{R T}$

In this work, the uncertainty in the energies of reactant and TS are set as \pm 1.0 and $\pm 2.0 \mathrm{kcal} / \mathrm{mol}$, respectively, and the $\Delta E_{R}$ and $\Delta E_{T S}$ values, which are the difference in the upper and lower limits, are then 2.0 and $4.0 \mathrm{kcal} / \mathrm{mol}$, respectively.

Table 4 lists the temperature dependent total uncertainty factors for $\mathrm{k}_{1}$ and $\mathrm{k}_{2}$ in the high pressure limit as determined by the HDMR simulations as well as the contribution from just the energy parameters. $U_{\mathrm{E} 1}$ represents the uncertainty factor obtained by multiplying the total uncertainty by the sensitivity indices for the energy parameters, while $U_{\mathrm{E} 2}$ is the one deduced from (E12) analytically. The numerical simulations and analytical derivations yield almost identical values, as shown in Table 4. The comparison between the total uncertainty and the partial uncertainty introduced by the energy parameters indicates that the uncertainty of the computed HPL rate constants mainly comes from the uncertainties of the energy parameters, which can also be seen from the sensitivity analysis in Fig. 2 and 3.

It is interesting to also consider the contribution of the frequency uncertainties to the uncertainty of the TST rate constants. At high temperature, the partition functions are proportional to these frequencies and the variance is given by a simple analog of $(\mathrm{E} 11)$, i.e., $\sigma_{v \mathrm{i}}=\left[\left(\Delta v_{\mathrm{i}}\right)^{2} / 12\right]^{1 / 2} / v_{\mathrm{i}}$ and $\sigma_{\mathrm{vib}}$ $=\left[\Sigma \sigma_{\mathrm{vi}}{ }^{2}\right]^{1 / 2}$. For R1 there are 4 vibrational modes and the net contribution to the variance is 0.11 , while for R2 there are 6 modes and the vibrational contribution of the variance is 0.14 . These variances map via (E11) into uncertainty factors of 1.25 and 1.31. There should also be a small contribution to the variance from the hindered rotor mode. Here, for the presumed uncertainties in the energies, these vibrational variances are swamped by the corresponding energy parameter variances, contributing only about 0.1 to the total variances in Table 4. For smaller energy uncertainties, the frequency uncertainties can be expected to play a more significant role. 


\subsubsection{Fall-off Pressures}

Table 5 lists the uncertainty factors for $\mathrm{k}_{1}$ and $\mathrm{k}_{2}$ at $1000 \mathrm{~K}$ and various pressures, while those at other temperatures and pressures are listed in the Supplemental Material. The uncertainty of $\mathrm{k}_{1}$ changes with temperature and pressure insignificantly. With the specified uncertainty set for the input parameters (see Table 1), the RRKM/ME rate constants of the dominant channel - R1 has uncertainty factors below 5 for temperatures ranging from 800 to $2000 \mathrm{~K}$ under various pressures. In contrast with the relatively stable and low uncertainty value for $k_{1}$, the uncertainty of $k_{2}$ increases dramatically with decreasing pressure, which also corresponds to the frequency distribution of the computed rate constants shown in Fig. 5. As indicated by the sensitivity analysis (see Fig. 3), the dominant uncertainty sources for the computed $\mathrm{k}_{2}$ consist of $\left\langle\Delta \mathrm{E}>_{\text {down }}\right.$ parameters, the TS2 energy and the TS1 energy. This sensitivity to both channel 1 and channel 2 parameters implies that the competition between the two channels has a significant impact on the uncertainty of $\mathrm{k}_{2}$.

The simple Lindemann mechanism [59] may shed light on the strong dependence of the uncertainty in the computed $\mathrm{k}_{2}$ on this competition. The Lindemann mechanism for a simple reaction system with two competing decomposition channels can be written as,

$$
\begin{gathered}
A+M \stackrel{k_{a,} k_{-a}}{\Longleftrightarrow} A^{*}+M \\
A^{*} \stackrel{k_{b}}{\rightarrow} P 1 \\
A^{*} \stackrel{k_{c}}{\rightarrow} P 2
\end{gathered}
$$

By using the steady state assumption for $\mathrm{A}^{*}$, the variance in the natural logarithm of the low pressure limit (LPL) rate constants for the two channels can be given as:

$$
\begin{aligned}
& D\left(\ln \mathrm{k}_{p 1}^{L P L}\right)=D\left\{\ln \frac{k_{b}}{k_{b}+k_{c}}\right\}+D\left(\ln k_{a}\right)+D(\ln [M]) \\
& D\left(\ln \mathrm{k}_{p 2}^{L P L}\right)=D\left\{\ln \frac{k_{c}}{k_{b}+k_{c}}\right\}+D\left(\ln k_{a}\right)+D(\ln [M])
\end{aligned}
$$


A detailed derivation of (E13) and (E14) is provided in the Supplemental Material. The uncertainty in the two rate constants are the same if $\mathrm{k}_{\mathrm{b}}$ is equal to $\mathrm{k}_{\mathrm{c}}$. However, with increasing energy gap the difference between $\mathrm{k}_{\mathrm{b}}$ and $\mathrm{k}_{\mathrm{c}}$ increases, and the two uncertainties differ quite significantly. In particular, if the $P 1$ channel makes the dominant contribution to the unimolecular decomposition (i.e., $\left.\mathrm{k}_{\mathrm{b}} \gg \mathrm{k}_{\mathrm{c}}\right)$, the first term variance vanishes in (E17), while $\mathrm{D}\left\{\ln \left(k_{c} / k_{b}\right)\right\}$ is an important uncertainty source for $\ln k_{2}$. Thus, the uncertainty of $\mathrm{k}_{2}$ can be much higher than that of $\mathrm{k}_{1}$.

The quantitative uncertainty of the rate constants in the fall-off region is not readily derived from simple mathematical formulae. Instead, a series of Monte Carlo simulations were designed to provide some indication of the quantitative relationship between the energy gap and the uncertainties in the rate constants for the two channels. For this purpose, we considered two identical reactions with input parameters set to those for R1 for both reactions, but with different barrier heights. The artificial reaction was named as $\mathrm{R} 1 \mathrm{a}$ here. The uncertainty analysis was performed while varying the energy of TS1a, consequently changing the energy gap between the two channels. In addition, we also examined the effect of the uncertainty in the $\langle\Delta \mathrm{E}\rangle_{\text {down }}$ prefactor by setting its uncertainty to be $\pm 20 \%$.

Figure 6 illustrates the results of these "experiments" at $1500 \mathrm{~K}, 0.1 \mathrm{~atm}$, where the horizontal axis is the energy gap between TS1 and TS1a, while the vertical axis is the logarithm of the uncertainty factor. The uncertainty of $\mathrm{k}_{1}$ is reduced by $\sim 10-30 \%$, and for $\mathrm{k}_{1 \mathrm{a}}$ it is reduced by $\sim 10-60 \%$ when the uncertainty of $\left\langle\Delta \mathrm{E}>_{\text {down }}\right.$ prefactor is reduced from $50 \%$ to $20 \%$. These variations appear to be only weakly dependent of the barrier difference. Figure 6 explicitly reveals the impact of the energy gap between the competing pathways on the uncertainty of their rate constants. With increasing energy gap, the uncertainty in the rate constant for the channel with the smaller contribution increases dramatically. When the energy gap between two reaction channels reaches 20 
$\mathrm{kcal} / \mathrm{mol}$, the uncertainty in the rate constant for $\mathrm{R} 1 \mathrm{a}$ is one order of magnitude greater than that for $\mathrm{R} 1$.

Figure 7 illustrates the variation in the overall uncertainty factors for $\mathrm{k}_{1}$ and $\mathrm{k}_{2}$ with temperature and pressure. Calculated nominal values and uncertainty bands (with 95\% confidence intervals) of the rate constants for $\mathrm{R} 1$ and $\mathrm{R} 2$ at $0.001,0.01,0.1,1$, and $10 \mathrm{~atm}$ are provided in the Supplemental Material. In general, the uncertainties of both $\mathrm{k}_{1}$ and $\mathrm{k}_{2}$ increase with decreasing pressure, due to the uncertainties introduced by the collisional model and the interaction between collisional energy transfer and chemical reaction. The impact of pressure and temperature on the uncertainty of $k_{2}$ is much greater than that for $\mathrm{k}_{1}$, because of the competition between collisional activation and dissociation for energies in the energy gap between TS1 and TS2. The apparent irregularities in temperature behavior for the uncertainty of $\mathrm{k}_{2}$ at temperatures of 900,1300 , and $1900 \mathrm{~K}$ are an artifact that can be explained by the presence of steps in the canonical variational TS location (cf. Fig. 1), which correlate with steps in the energy difference between TS1 and TS2. From the location of the variational TS shown in Fig. 1, one finds that the barrier height of TS2 is 83.04, 80.30, 77.31, and $75.27 \mathrm{kcal} / \mathrm{mol}$ at $800,900-1200,1300-1800$, and $1900-2000 \mathrm{~K}$, respectively. This change in the variational barrier height for TS2 affects the competition between the two channels and the collisional activation process, and consequently affects the uncertainties of $\mathrm{k}_{2}$. As was stated above, while the CVT treatment may bring modest deviations to the computed rate constant, it does allow us to perform the HDMR analysis with affordable computational cost. Moreover, the intuitive physical picture of the CVT calculations allows us to explore deeply the influence of the competition between the two reaction channels on the uncertainty of the RRKM/ME rate constants.

A physical consideration of the competition between collisional activation and dissociation helps explain the observed temperature and pressure dependence for the uncertainty in $\mathrm{k}_{2}$. In the low 
pressure limit, every molecule that gets collisionally activated above the dissociation threshold will dissociate prior to another collision. Thus, the dissociation to a higher energy channel (in this low pressure limit) requires a single step collisional excitation from below the threshold of the lower energy channel to above the threshold of the higher energy channel. Within the present master equation model, the probability of this occurring is roughly proportional to exp[-( $\left.\mathrm{E}_{\mathrm{TS} 2}-\mathrm{E}_{\mathrm{TS} 1}\right) /$ $\left.<\Delta \mathrm{E}>_{\text {down }}\right]$. The uncertainties in this probability have an exponential dependence on the uncertainties in both the transition state energies as well as on the energy transfer parameter. The probability is very small for large energy differences and its uncertainty can readily be a few orders of magnitude for the $\mathrm{C}_{2} \mathrm{H}_{5} \mathrm{OH}$ system. Notably, for larger $\left\langle\Delta \mathrm{E}>_{\text {down }}\right.$ values, as occur at higher temperature, the uncertainty in this probability is smaller, as observed. Interestingly, with increasing pressure, the collisional activation can occur through multiple collisions and the strong dependence on the energy transfer parameters is ameliorated. In the high pressure limit, collisions are so frequent that a Boltzmann population of excited molecules is maintained at all energies and the dependence on the energy transfer parameters completely disappears.

The propagation of the uncertainty from the various input parameters to that of the computed rate constants is very complicated, with some of them having a positive influence while others have a negative influence. It is interesting to separate those parameters into energy parameters (including energies of the reactant and transition states), collisional parameters (including $\mathrm{CH}_{3} \mathrm{CH}_{2} \mathrm{OH}$ $<\Delta \mathrm{E}>_{\text {down }}$ prefactor and T-exponent, Ar L-J parameters, $\mathrm{CH}_{3} \mathrm{CH}_{2} \mathrm{OH}$ L-J parameters) and frequency parameters (including TS imaginary frequency, vibration frequency etc.). Figure 8 shows the uncertainty brought by the energy and collisional parameters for both reactions, respectively. The frequency parameters have very minor sensitivities in this case, which are omitted here. Apparently, the uncertainty of $k_{1}$ from the energy parameters decreases with temperature, while that from 
collisional parameters has the opposite tendency. The partial uncertainties of $k_{2}$ from the energy parameters generally decrease with temperature, however, several irregular steps are observed because of the variational energy barriers, as discussed above. The temperature dependence of the uncertainties in $k_{2}$ introduced by the collisional parameters is more complicated due to the additional influence of the competition between collisional activation and the dissociations. It is desirable to perform detailed global uncertainty analysis on general reactions with a focus on the temperature and pressure dependence of the partial uncertainties originating from energy parameters, frequency parameters and collisional parameters etc, as will be pursued in our future work.

\section{Conclusions}

The propagation of uncertainty during RRKM/ME calculations was studied using the ethanol decomposition as a case study. The temperature and pressure dependent kinetics of ethanol decomposition, which includes two dominant pathways, i.e., $\mathrm{H}_{2} \mathrm{O}$ elimination and barrierless C-C bond fission, was investigated by canonical variational transition state theory coupled with the RRKM/ME approach. Selected uncertainties in the important input parameters were propagated to uncertainty factors for the overall rate constants via a global sensitivity and uncertainty analysis that was performed with the RS-HDMR method.

According to the sensitivity analysis, the second-order sensitivities are very small for the studied reaction for a wide range of temperature and pressure. The energy transfer parameter $\left.(<\Delta \mathrm{E}\rangle_{\text {down }}\right)$, and the reactant and transition state energies have the largest contributions to the uncertainty of the rate constants for both channels. The difference in the sensitivities for the two channels is determined by the competition between collisional activation and dissociation. The computed rate constants have very similar uncertainty factors for the two reactions in the high pressure limit. These HPL 
uncertainties are controlled by the reactant and TS energies for the case of ethanol decomposition. At falloff pressure conditions, the uncertainties in the rate constants for $\mathrm{C}-\mathrm{C}$ bond fission are significantly greater than those for the $\mathrm{H}_{2} \mathrm{O}$ elimination rate constants. The former uncertainties are related to the uncertainties in the collisional energy transfer parameters and more importantly by the energy gap between the two transition states.

Although the decomposition of ethanol was chosen as a case study, the conclusions obtained in this work are not limited to this specific case. Instead, this work provides a useful indication of the typical parametric uncertainties in RRKM/ME calculations for general reaction systems, especially for those with two or more competing channels. Nevertheless, the uncertainty sources, temperature and pressure dependence, etc., may vary for different reaction systems, which then need further global uncertainty analyses. For instance, the frequency parameters may contribute more uncertainties for the RRKM/ME rate constants of reaction systems with more low frequencies than ethanol decomposition.

The HDMR method provides a great tool for investigating the propagation of uncertainty through RRKM/ME calculations. The parametric uncertainty analysis of the RRKM/master equation rate constants in this work provides valuable information for evaluating the accuracy of the computed rate constants. Further uncertainty evaluations are strongly needed for theoretical investigations of the temperature and pressure dependent kinetics of complex reaction systems with multiple competing reaction channels.

\section{Note}

$\dagger$ Lili Xing and Shuang Li contributed equally to this work. 


\section{Acknowledgements}

This work is supported by National Natural Science Foundation of China, in part under grants 51376170 (F.Z., L.X., Z.W.) and U1332208 (B.Y., S. L). This material is based in part on work at Argonne supported by the U.S. Department of Energy, Office of Science, Office of Basic Energy Sciences, Division of Chemical Sciences, Geosciences, and Biosciences under Contract No. DE-AC02-06CH11357. We greatly appreciate the help provided by Dr. Michael Pilling and Dr. Robin Shannon in using the MESMER program and by Alison Tomlin in using the GUI-HDMR code. We also appreciate Dr. Fei Qi for his kind help.

\section{References}

1. C. Yin, R. Guo, J. Du, Physica A 408 (2014) 85.

2. U. Lourderaj, W. L. Hase, J. Phys. Chem. A 113 (2009) 2236.

3. A. Maranzana, J. R. Barker, G. Tonachini, Phys. Chem. Chem. Phys. 9 (2007) 4129.

4. J. R. Barker, D. M. Golden, Chem. Rev. 103 (2003) 4577.

5. E. Martinez-Nunez, S. A. Vazquez, Quim. Nova 25 (2002) 579.

6. S. Nordholm, A. Back, Phys. Chem. Chem. Phys. 3 (2001) 2289.

7. C. Lifshitz, Chem. Soc. Rev. 30 (2001) 186.

8. D. L. Thompson, Int. Rev. Phys. Chem. 17 (1998) 547.

9. J. Troe, J. Chem. Phys. 97 (1992) 288.

10. Z. Wang, Y. Li, F. Zhang, L. Zhang, W. Yuan, Y. Wang, F. Qi, Proc. Combust. Inst. 34 (2013) 1785.

11. V. V. Kislov, A. M. Mebel, J. Aguilera-Iparraguirre, W. H. Green, J. Phys. Chem. A 116 (2012) 4176.

12. A. Jamal, A. M. Mebel, Chem. Phys. Lett. 518 (2011) 29.

13. A. Jamal, A. M. Mebel, J. Phys. Chem. A 115 (2011) 2196.

14. J. Kiecherer, C. Bänsch, T. Bentz, M. Olzmann, Proc. Combust. Inst. 35 (2015) 465.

15. R. Sivaramakrishnan, M. C. Su, J. V. Michael, S. J. Klippenstein, L. B. Harding, B. Ruscic, J. Phys. Chem. A 114 (2010) 9425 .

16. S. J. Klippenstein, Y. Georgievskii, L. B. Harding, Phys. Chem. Chem. Phys. 8 (2006) 1133.

17. A. W. Jasper, N. Hansen, Proc. Comb. Inst. 34 (2013) 279.

18. H. Rabitz, Ö. F. Aliş, J. Math. Chem. 25 (1999) 197.

19. H. Rabitz, Ö. F. Aliş, J. Shorter, K. Shim, Comput. Phys. Commun. 117 (1999) 11.

20. Ö. Alış, H. Rabitz, J. Math. Chem. 29 (2001) 127.

21. G. Li, C. Rosenthal, H. Rabitz, J. Phys. Chem. A 105 (2001) 7765.

22. G. Li, S.-W. Wang, H. Rabitz, J. Phys. Chem. A 106 (2002) 8721.

23. G. Li, S. W. Wang, H. Rabitz, S. Wang, P. Jaffé, Chem. Eng. Sci. 57 (2002) 4445.

24. G. Li, H. Rabitz, S. W. Wang, P. G. Georgopoulos, J. Comput. Chem. 24 (2003) 277.

25. G. Li, H. Rabitz, J. Comput. Chem. 27 (2006) 1112.

26. T. Ziehn, A. S. Tomlin, Environ. Modell. Softw. 24 (2009) 775.

27. T. Ziehn, A. S. Tomlin, Int. J. Chem. Kinet. 40 (2008) 742.

28. T. Ziehn, A. S. Tomlin, Atmos. Environ. 42 (2008) 1857.

29. C. F. Goldsmith, A. S. Tomlin, S. J. Klippenstein, Proc. Combust. Inst. 34 (2013) 177. 
30. J. Park, R. S. Zhu, M. C. Lin, J. Chem. Phys. 117 (2002) 3224.

31. J. Park, Z. F. Xu, K. Xu, M. C. Lin, Proc. Combust. Inst. 34 (2013) 473.

32. Z. F. Xu, K. Xu, M. C. Lin, J. Phys. Chem. A. 115 (2011) 3509.

33. C. W. Wu, H. Matsui, N. S. Wang, M. C.Lin, J. Phys. Chem. A 115 (2011) 8086.

34. N. Leplat, P. Dagaut, C. Togbé, J. Vandooren, Combust. Flame 158 (2011) 705.

35. R. Grana, A. Frassoldati, T. Faravelli, U. Niemann, E. Ranzi, R. Seiser, R. Cattolica, K. Seshadri, Combust. Flame 157 (2010) 2137.

36. J.-H. Wang, C. S. Lee, M. C. Lin, J. Phys. Chem. C 113 (2009) 6681.

37. M. H. Matus, M. T. Nguyen, D. A. Dixon, J. Phys. Chem. A 111 (2007) 113.

38. S. J. Klippenstein, J. Chem. Phys. 96 (1992) 367.

39. D. G. Truhlar, B. C. Garrett, Acc. Chem. Res. 13 (1980) 440.

40. M. Olzmann, Phys. Chem. Chem. Phys. 4 (2002) 3614.

41. J. M. L. Martin, O. Uzan, Chem. Phys. Lett. 282 (1998) 16.

42. M. J. Frisch, G. W. Trucks, H. B. Schlegel, G. E. Scuseria, M. A. Robb, Gaussian 09, Revision B.01, Gaussian Inc., Wallingford, CT, 2009.

43. H. J. Werner, P. J. Knowles, G. Knizia, F. R. Manby, M. Schutz, MOLPRO, version 2010.1; www.molpro.net.

44. G. d. Silva, J. W.Bozzelli, J. Phys. Chem. A 112 (2008) 3566.

45. C. Eckart, Phys. Rev. 35 (1930) 1303.

46. M. J. Pilling, S. H. Robertson, Annu. Rev. Phys. Chem. 54 (2003) 245.

47. J. R. Welty, C. E. Wicks, R. E. Wilson, G.L. Rorrer, Fundamentals of Momentum Heat and Mass Transfer, John Wiley \& Sons Ltd., New York, 2001.

48. B. E. Poling, J. M. Prausnitz, J. P. O’Connell, The Properties of Gases and Liquids, McGraw-Hill, Inc., New York, 2001.

49. F. M. Mourits, F. H. A. Rummens, Can. J. Chem. 55 (1977) 3007.

50. D. R. Glowacki, C. H. Liang, C. Morley, M. J. Pilling, S. H. Robertson, J. Phys. Chem. A 116 (2012) 9545.

51. S. H. Robertson, R. Shannon, P. W. Seakins, M. J. Pilling, MESMER (Master Equation Solver for Multi-Energy Well Reactions), 2008-2013; an object oriented C++ program implementing master equation methods for gas phase reactions with arbitrary multiple wells. http://sourceforge.net/projects/mesmer.

52. A. W. Jasper, C. M. Oana, J. A. Miller, Proc. Combust. Inst. 35 (2015) 197.

53. A. W. Jasper, K. M. Pelzer, J. A. Miller, E. Kamarchik, L. B. Harding, S. J. Klippenstein, Science 346 (2014) 1212.

54. A. W. Jasper, J. A. Miller, Combust. Flame 161 (2014) 101.

55. A. W. Jasper, J. A. Miller, The Journal of Physical Chemistry A 115 (2011) 6438.

56. J. Prager, H. N. Najm, K. Sargsyan, C. Safta, W. J. Pitz, Combust. Flame 160 (2013) 1583.

57. M. T. Reagan, H. N. Najm, P. P. Pébay, O. M. Knio, R. G. Ghanem, Int. J. Chem. Kinet. 37 (2005) 368.

58. M. T. Reagan, H. N. Najma, R. G. Ghanemb, O. M. Kniob, Combust. Flame 132 (2003) 545.

59. R. G. GILBERT, S. C. SMITH, Theory of Unimolecular and Recombination Reactions, BLACKWELL SCIENTIFIC PUBLICATIONS, 1990. 


\section{Figure Captions}

Figure 1. Calculated minimum energy pathway for the decomposition channel $\mathrm{R} 2\left(\mathrm{C}_{2} \mathrm{H}_{5} \mathrm{OH} \rightarrow \mathrm{CH}_{3}\right.$ $\left.+\mathrm{CH}_{2} \mathrm{OH}\right)$ at the CASPT2(2e,2o)/cc-pVDZ level, scaled to the QCISD(T)/CBS dissociation energy. The circles indicate the location of the variational transition state as a function of temperature.

Figure 2. The most significant first-order sensitivities for $\mathrm{k} 1(\mathrm{CH} 3 \mathrm{CH} 2 \mathrm{OH} \rightarrow \mathrm{C} 2 \mathrm{H} 4+\mathrm{H} 2 \mathrm{O})$ in the temperature range of $800-2000 \mathrm{~K}$ and pressures of $0.001,0.01,0.1,1,10 \mathrm{~atm}$ and the high pressure limit (HPL), respectively.

Figure 3. The most significant first order sensitivities for $\mathrm{k}_{2}\left(\mathrm{CH}_{3} \mathrm{CH}_{2} \mathrm{OH} \rightarrow \mathrm{CH}_{3}+\mathrm{CH}_{2} \mathrm{OH}\right)$ in the temperature range of $800-2000 \mathrm{~K}$ and pressures of $0.001,0.01,0.1,1,10 \mathrm{~atm}$ and the high pressure limit (HPL), respectively.

Figure 4. Normalized distribution of (a) $\mathrm{k}_{2}$ and (b) $\ln k_{2}$ computed by the RRKM/ME method at 1500 $\mathrm{K}$ and 0.01 atm with randomly sampled input parameters. $\mathrm{k}_{2}$ is the rate constant for $\mathrm{R} 2\left(\mathrm{C}_{2} \mathrm{H}_{5} \mathrm{OH} \rightarrow\right.$ $\left.\mathrm{CH}_{3}+\mathrm{CH}_{2} \mathrm{OH}\right)$.

Figure 5. Normalized frequency distribution $\log _{10}\left(\mathrm{k} / \mathrm{k}_{\text {nominal }}\right)$ for the predicted rate constants at 1500 $\mathrm{K}$ and either $0.01 \mathrm{~atm}$ or the HPL (high pressure limit).

Figure 6. Logarithm of the uncertainty factors as a function of the energy gap between TS1 $\left(\mathrm{CH}_{3} \mathrm{CH}_{2} \mathrm{OH} \rightarrow \mathrm{C}_{2} \mathrm{H}_{4}+\mathrm{H}_{2} \mathrm{O}\right)$ and TS1a at $1500 \mathrm{~K}, 0.1$ atm. The reaction $\mathrm{R} 1 \mathrm{a}$ was artificially 
designed to have exactly the same input parameters as R1, except for the barrier height. The black and blue lines represent cases with different uncertainties for the $\left\langle\Delta \mathrm{E}>_{\text {down }}\right.$ prefactor; triangle and square symbols represent R1a and R1 respectively.

Figure 7. The natural logarithm of the uncertainty factors for $\mathrm{k}_{1}\left(\mathrm{CH}_{3} \mathrm{CH}_{2} \mathrm{OH} \rightarrow \mathrm{C}_{2} \mathrm{H}_{4}+\mathrm{H}_{2} \mathrm{O}\right)$ and $\mathrm{k}_{2}$ $\left(\mathrm{CH}_{3} \mathrm{CH}_{2} \mathrm{OH} \rightarrow \mathrm{CH}_{3}+\mathrm{CH}_{2} \mathrm{OH}\right)$ at temperatures ranging from 800-2000 $\mathrm{K}$ and five pressures.

Figure 8. The natural logarithm of the contributions to the uncertainty factors for $\mathrm{k}_{1}\left(\mathrm{CH}_{3} \mathrm{CH}_{2} \mathrm{OH} \rightarrow\right.$ $\left.\mathrm{C}_{2} \mathrm{H}_{4}+\mathrm{H}_{2} \mathrm{O}\right)$ and $\mathrm{k}_{2}\left(\mathrm{CH}_{3} \mathrm{CH}_{2} \mathrm{OH} \rightarrow \mathrm{CH}_{3}+\mathrm{CH}_{2} \mathrm{OH}\right)$ from the energy parameters (including energies of the reactant and transition states) and the collision parameters (including $\mathrm{C}_{2} \mathrm{H}_{5} \mathrm{OH}<\Delta \mathrm{E}>_{\text {down }}$ prefactor and T-exponent, Ar L-J parameters, and $\mathrm{C}_{2} \mathrm{H}_{5} \mathrm{OH}$ L-J parameters). 
Table 1. The input parameters and their uncertainties used in the RS-HDMR analysis

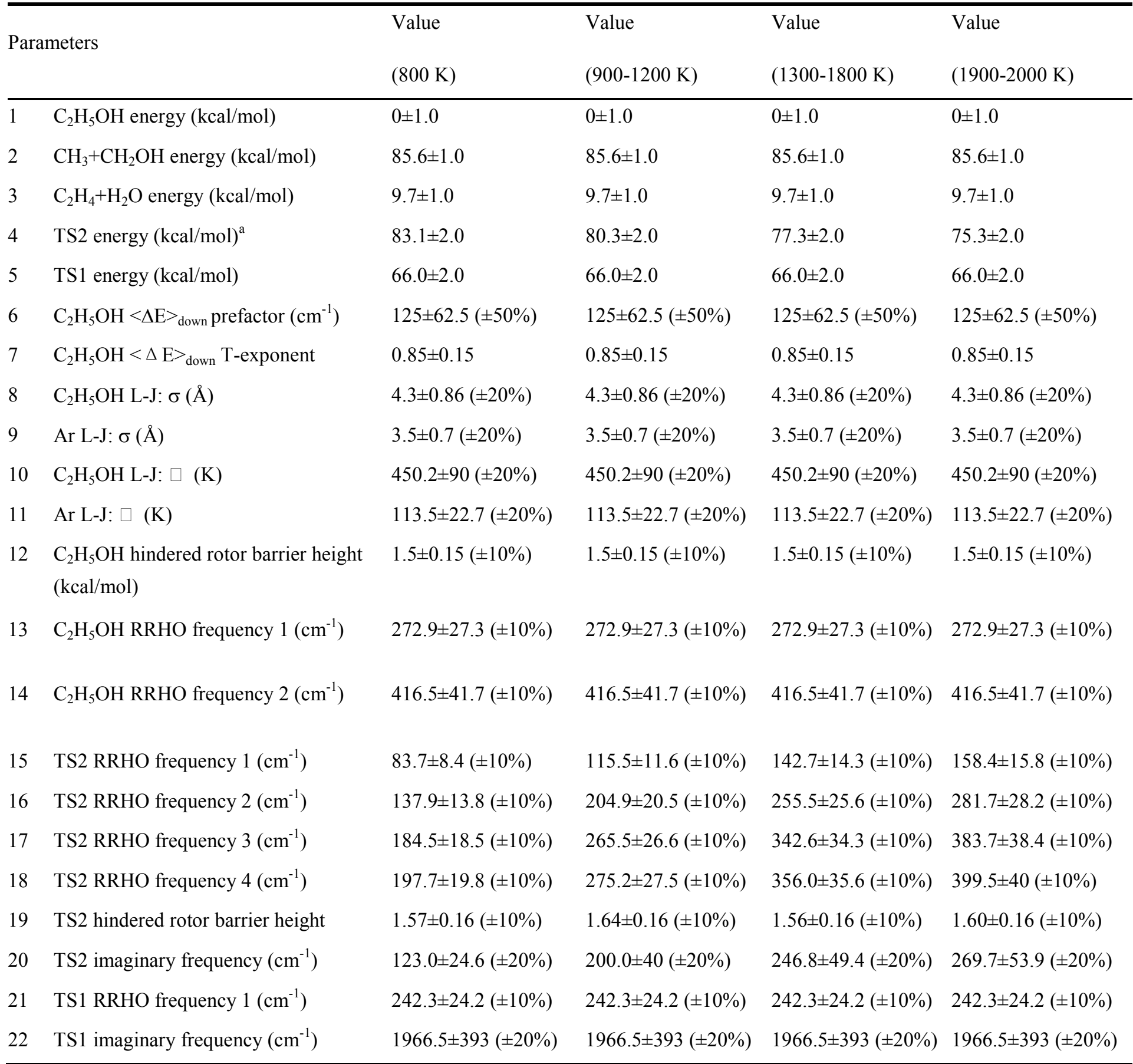

a. TS2 energy varies with temperature due to the use of canonical variational transition state theory. 
Table 2. Stationary point energies for the decomposition of $\mathrm{C}_{2} \mathrm{H}_{5} \mathrm{OH}^{\mathrm{a}}$

\begin{tabular}{|c|c|c|c|}
\hline $\begin{array}{l}\text { Stationary } \\
\text { Point }\end{array}$ & $\begin{array}{l}\text { QCISD(T)/CBS }{ }^{\mathrm{b}} \\
/ / \mathrm{B} 3 \mathrm{LYP} / 6-311++\mathrm{G} \\
* *\end{array}$ & $\begin{array}{l}\text { G2M }{ }^{\mathrm{c}} \\
/ / \mathrm{B} 3 \mathrm{LYP} / 6-311 \mathrm{G}(\mathrm{d}, \\
\text { p) }\end{array}$ & $\begin{array}{l}\text { CCSD(T)-F12/def2-QZV } \\
\mathrm{PP}^{\mathrm{d}} \\
/ / \mathrm{MP} 2 / \text { cc-pVQZ }\end{array}$ \\
\hline $\begin{array}{l}\mathrm{CH}_{3}+\mathrm{CH}_{2} \mathrm{O} \\
\mathrm{H}\end{array}$ & 85.6 & 87.5 & 85.7 \\
\hline $\mathrm{C}_{2} \mathrm{H}_{4}+\mathrm{H}_{2} \mathrm{O}$ & 9.7 & 6.5 & 10.0 \\
\hline TS1 & 66.0 & 66.6 & 66.6 \\
\hline
\end{tabular}

\footnotetext{
${ }^{\mathrm{a}}$ In $\mathrm{kcal} / \mathrm{mol}$ relative to the most stable conformer of $\mathrm{C}_{2} \mathrm{H}_{5} \mathrm{OH}$ including zero-point energy corrections. ${ }^{\mathrm{b}}$ From reference $15 .{ }^{\mathrm{c}}$ From reference $30 .{ }^{\mathrm{d}}$ From reference 14.
} 
Table 3. Major first- and second-order sensitivities of $\mathrm{k}_{1}$ and $\mathrm{k}_{2}$ at $1500 \mathrm{~K}$ and various pressures

\begin{tabular}{|c|c|c|c|c|c|c|c|c|c|c|}
\hline \multirow[b]{2}{*}{ Parameters } & \multirow[b]{2}{*}{$\begin{array}{l}0.001 \\
\text { atm }\end{array}$} & \multicolumn{5}{|c|}{$\mathrm{R} 1$} & \multicolumn{4}{|c|}{$\mathrm{R} 2$} \\
\hline & & $0.01 \mathrm{~atm}$ & $0.1 \mathrm{~atm}$ & $1 \mathrm{~atm}$ & $10 \mathrm{~atm}$ & $\begin{array}{l}0.001 \\
\text { atm }\end{array}$ & $\begin{array}{l}0.01 \\
\text { atm }\end{array}$ & $0.1 \mathrm{~atm}$ & $1 \mathrm{~atm}$ & $10 \mathrm{~atm}$ \\
\hline $\mathrm{C}_{2} \mathrm{H}_{5} \mathrm{OH}\langle\Delta \mathrm{E}\rangle_{\text {down }}$ prefactor & 0.558 & 0.446 & 0.286 & 0.136 & 0.047 & 0.319 & 0.319 & 0.337 & 0.318 & 0.204 \\
\hline $\begin{array}{l}\mathrm{C}_{2} \mathrm{H}_{5} \mathrm{OH}<\Delta \mathrm{E}>_{\text {down }} \\
\text { T-exponent }\end{array}$ & 0.112 & 0.089 & 0.057 & 0.028 & 0.010 & 0.063 & 0.063 & 0.067 & 0.063 & 0.040 \\
\hline TS1 energy & 0.221 & 0.342 & 0.509 & 0.657 & 0.741 & 0.277 & 0.229 & 0.154 & 0.074 & 0.021 \\
\hline TS2 energy & 0.000 & 0.000 & 0.000 & 0.009 & 0.006 & 0.281 & 0.311 & 0.359 & 0.455 & 0.589 \\
\hline $\mathrm{C}_{2} \mathrm{H}_{5} \mathrm{OH}$ energy & 0.053 & 0.074 & 0.101 & 0.128 & 0.155 & 0.000 & 0.000 & 0.011 & 0.041 & 0.098 \\
\hline $\mathrm{C}_{2} \mathrm{H}_{5} \mathrm{OH}$ L-J: $\sigma$ & 0.029 & 0.023 & 0.015 & 0.007 & 0.003 & 0.014 & 0.016 & 0.017 & 0.017 & 0.011 \\
\hline Ar L-J: $\sigma$ & 0.019 & 0.016 & 0.010 & 0.005 & 0.002 & 0.008 & 0.010 & 0.011 & 0.011 & 0.007 \\
\hline TS1 imaginary frequency & 0.009 & 0.000 & 0.000 & 0.000 & 0.000 & 0.006 & 0.004 & 0.002 & 0.001 & 0.000 \\
\hline TS1 RRHO frequency 1 & 0.000 & 0.002 & 0.004 & 0.007 & 0.010 & 0.002 & 0.000 & 0.000 & 0.000 & 0.000 \\
\hline $\begin{array}{l}\mathrm{C}_{2} \mathrm{H}_{5} \mathrm{OH}\langle\Delta \mathrm{E}\rangle_{\text {down }} \text { prefactor } \\
\text { \&TS2 energy }\end{array}$ & 0.000 & 0.000 & 0.000 & 0.000 & 0.000 & 0.004 & 0.002 & 0.002 & 0.002 & 0.000 \\
\hline TS1 energy \& TS2 energy & 0.000 & 0.000 & 0.000 & 0.000 & 0.000 & 0.002 & 0.002 & 0.003 & 0.002 & 0.000 \\
\hline $\begin{array}{l}\mathrm{C}_{2} \mathrm{H}_{5} \mathrm{OH}<\Delta \mathrm{E}>_{\text {down }} \text { prefactor } \\
\text { \&TS1 energy }\end{array}$ & 0.000 & 0.001 & 0.000 & 0.000 & 0.000 & 0.006 & 0.005 & 0.004 & 0.003 & 0.000 \\
\hline
\end{tabular}


Table 4. Temperature dependence of uncertainty factors for HPL rate constants

\begin{tabular}{cccccc}
\hline $\mathrm{T}(\mathrm{K})$ & $\mathrm{U}_{\mathrm{T}}\left(\mathrm{k}_{1}\right)^{\mathrm{a}}$ & $\mathrm{U}_{\mathrm{T}}\left(\mathrm{k}_{2}\right)$ & $\mathrm{U}_{\mathrm{E} 1}\left(\mathrm{k}_{1}\right)^{\mathrm{b}}$ & $\mathrm{U}_{\mathrm{E} 1}\left(\mathrm{k}_{2}\right)$ & $\mathrm{U}_{\mathrm{E} 2}(\mathrm{k})^{\mathrm{c}}$ \\
\hline 800 & 5.0 & 5.0 & 4.8 & 4.9 & 4.9 \\
900 & 4.2 & 4.2 & 4.1 & 4.1 & 4.1 \\
1000 & 3.6 & 3.7 & 3.5 & 3.6 & 3.6 \\
1100 & 3.2 & 3.3 & 3.2 & 3.2 & 3.2 \\
1200 & 2.9 & 3.0 & 2.9 & 2.9 & 2.9 \\
1300 & 2.7 & 2.7 & 2.7 & 2.7 & 2.7 \\
1400 & 2.5 & 2.6 & 2.5 & 2.5 & 2.5 \\
1500 & 2.4 & 2.4 & 2.3 & 2.3 & 2.4 \\
1600 & 2.3 & 2.3 & 2.2 & 2.2 & 2.2 \\
1700 & 2.2 & 2.2 & 2.1 & 2.1 & 2.1 \\
1800 & 2.1 & 2.1 & 2.0 & 2.0 & 2.0 \\
1900 & 2.1 & 2.1 & 2.0 & 2.0 & 2.0 \\
2000 & 1.9 & 2.0 & 1.9 & 1.9 & 1.9 \\
\hline
\end{tabular}

${ }^{\mathrm{a}} \mathrm{U}_{\mathrm{T}}$ represents the total uncertainty factors for $\mathrm{k}_{1}$ and $\mathrm{k}_{2}$ as determined by the Monte Carlo simulations. ${ }^{b} \mathrm{U}_{\mathrm{E} 1}$ represents the uncertainty computed from the energy parameters by multiplying the total uncertainty with the sensitivity indices for only the energy parameters. ${ }^{c} \mathrm{U}_{\mathrm{E} 2}(\mathrm{k})$ represents the uncertainties arising from just the energy parameters, which is deduced from (E12). 
Table 5. Uncertainty factors for $\mathrm{k}_{1}$ and $\mathrm{k}_{2}$ at $1000 \mathrm{~K}$ and a variety of pressures.

\begin{tabular}{lllllll}
\hline \multicolumn{7}{c}{ Uncertainty factors } \\
\hline & $0.001 \mathrm{~atm}$ & $0.01 \mathrm{~atm}$ & $0.1 \mathrm{~atm}$ & $1 \mathrm{~atm}$ & $10 \mathrm{~atm}$ & $\mathrm{HPL}$ \\
\hline $\mathrm{k}_{1}$ & 3.4 & 3.4 & 3.5 & 3.6 & 3.6 & 3.6 \\
\hline $\mathrm{k}_{2}$ & 163.4 & 23.4 & 7.5 & 4.4 & 3.7 & 3.7 \\
\hline
\end{tabular}




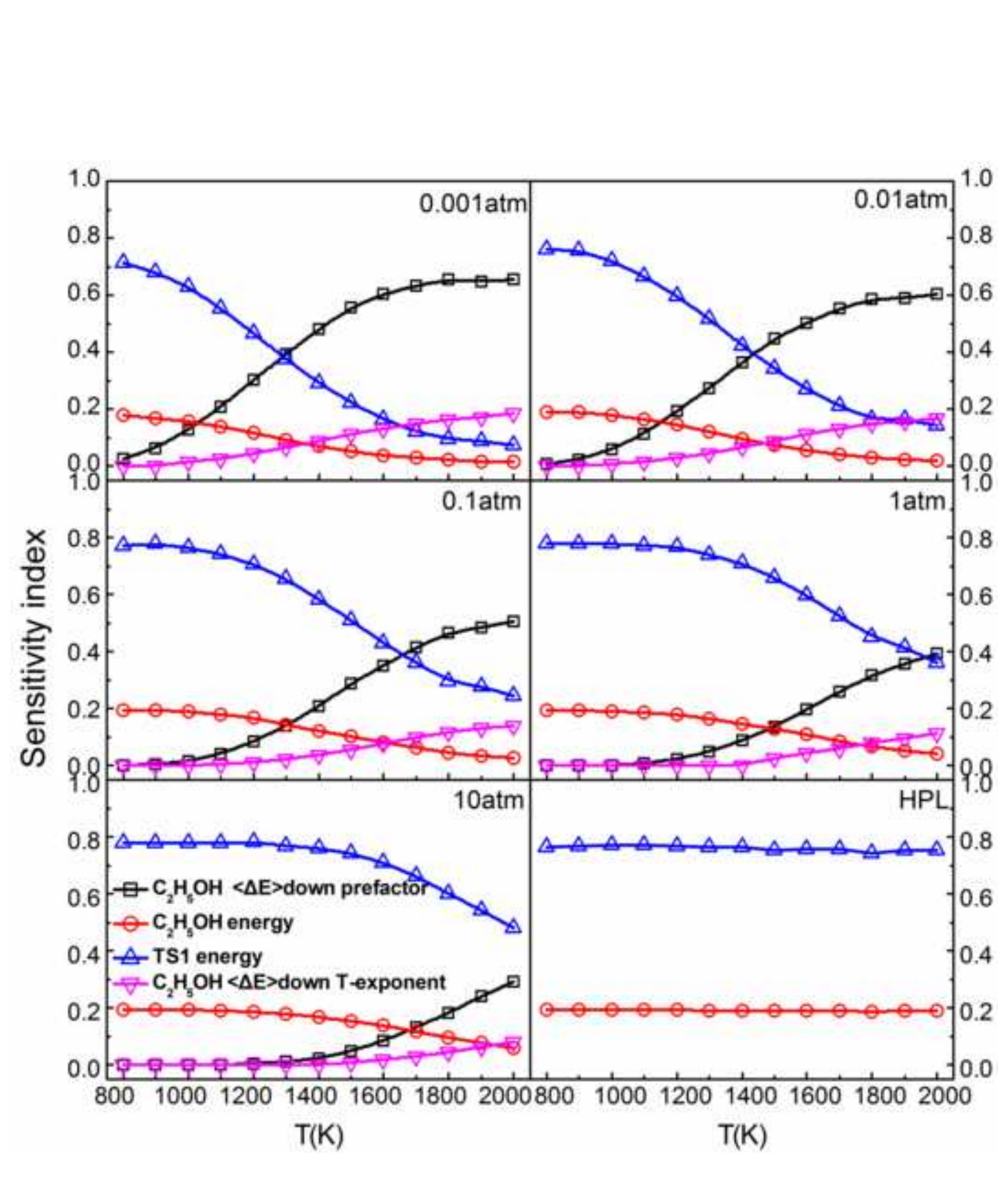

Figure 2

0

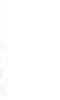

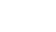

\section{Figure}

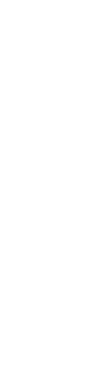




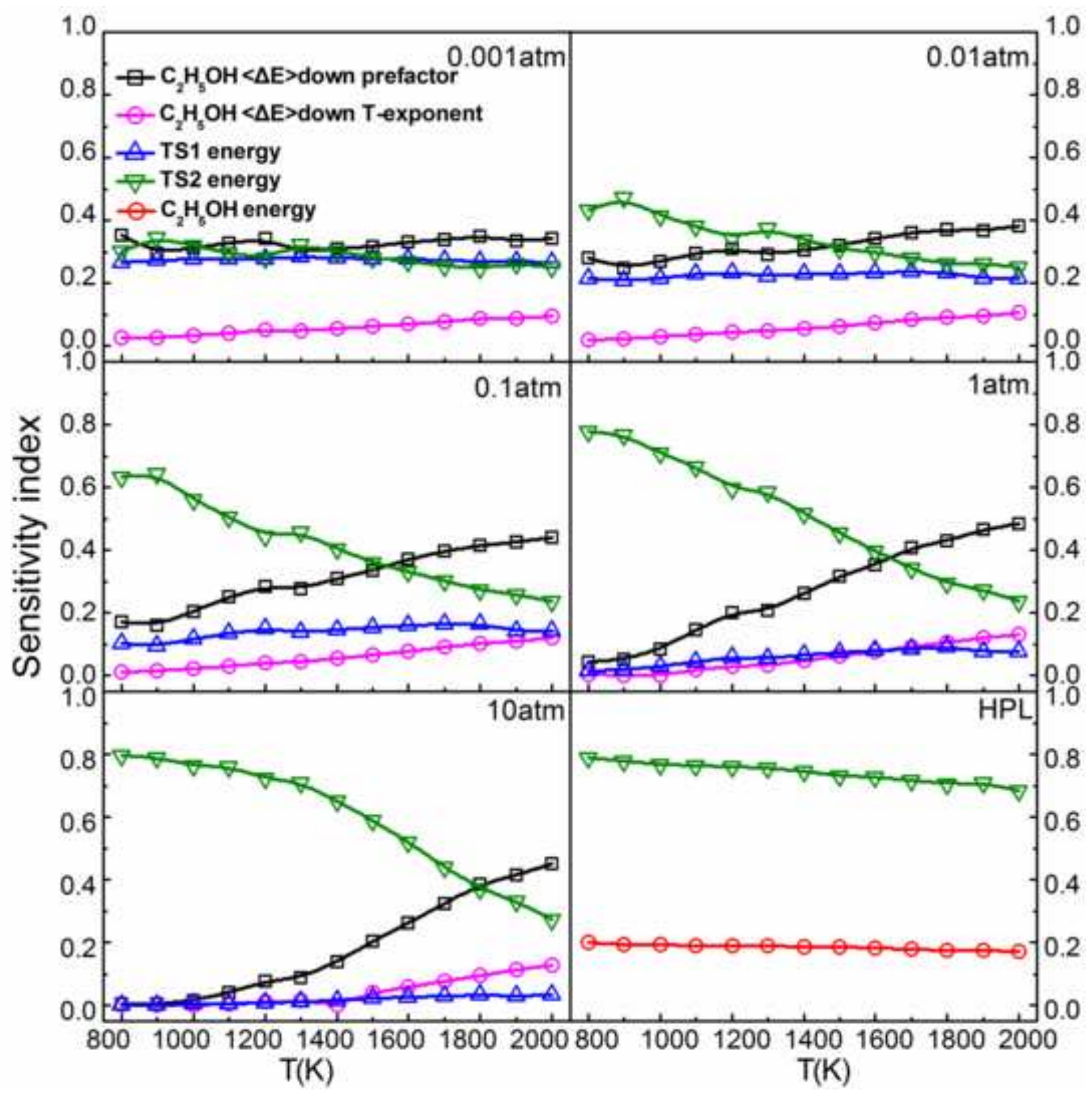




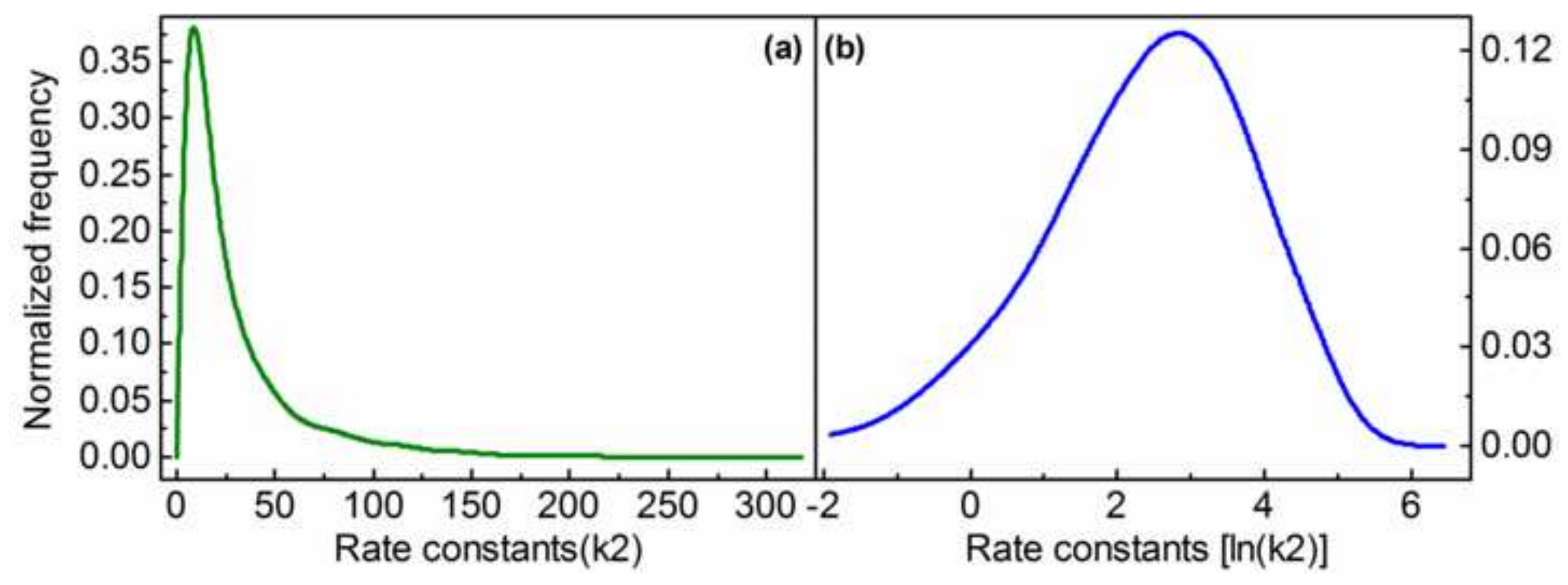




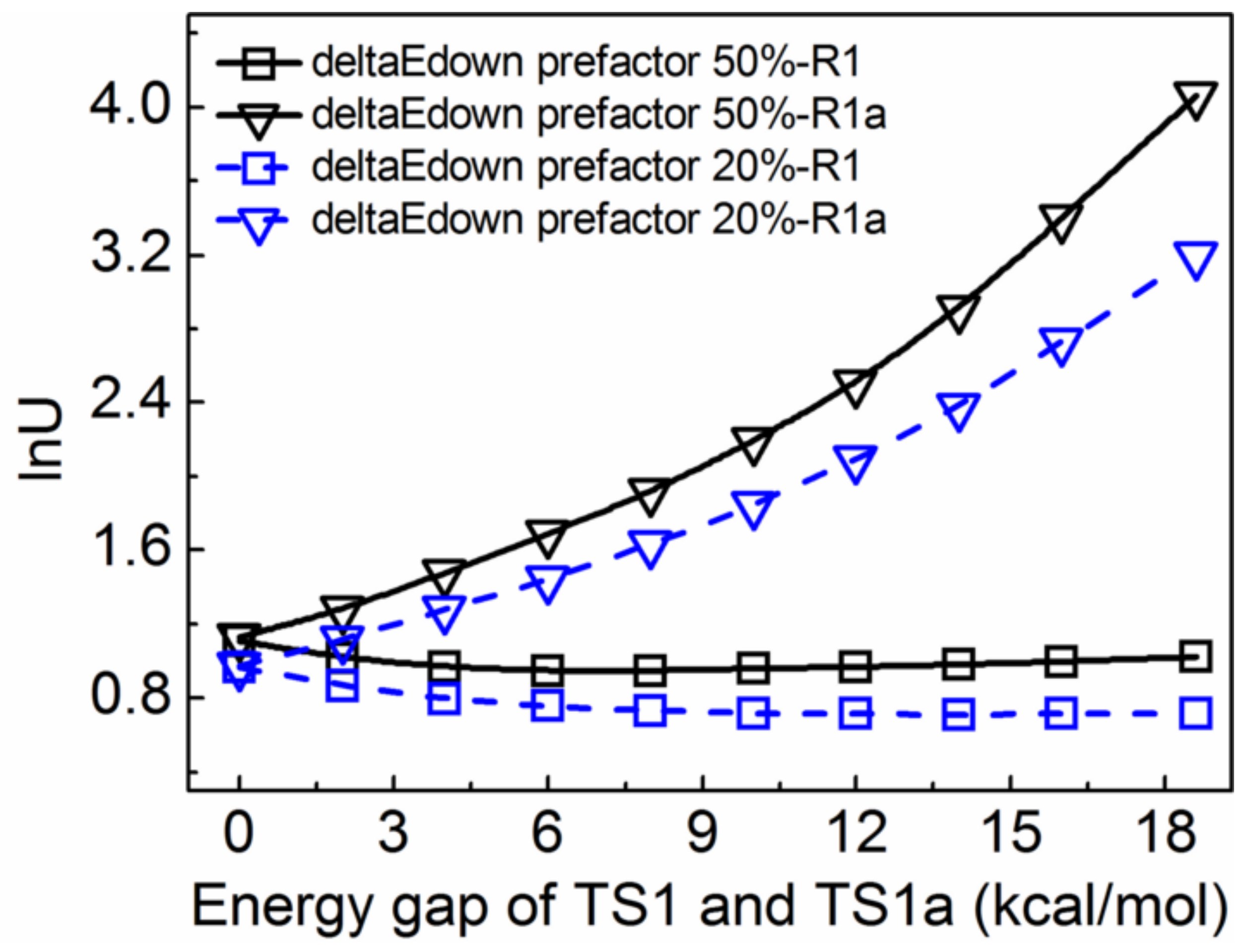




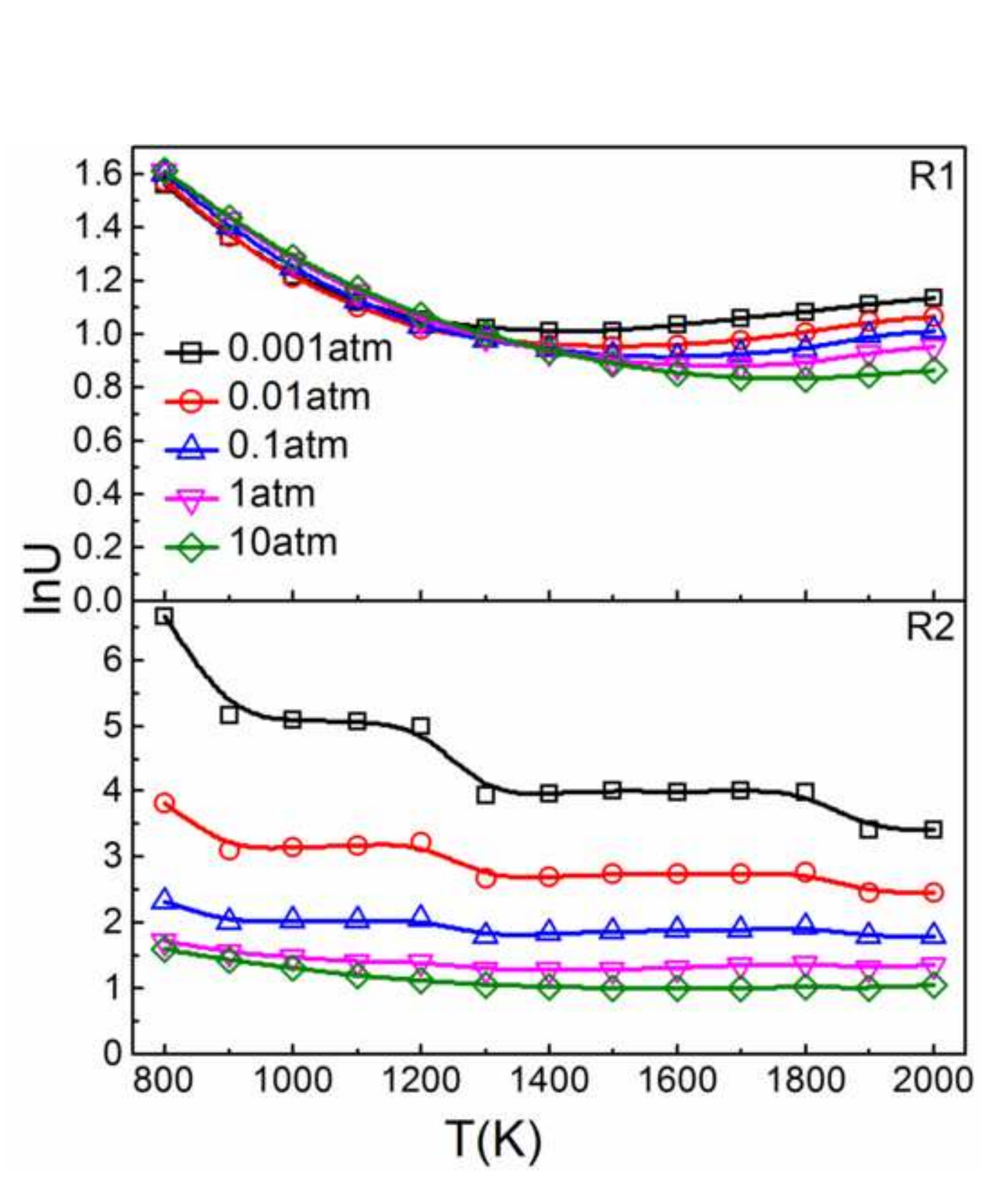

Figure 7
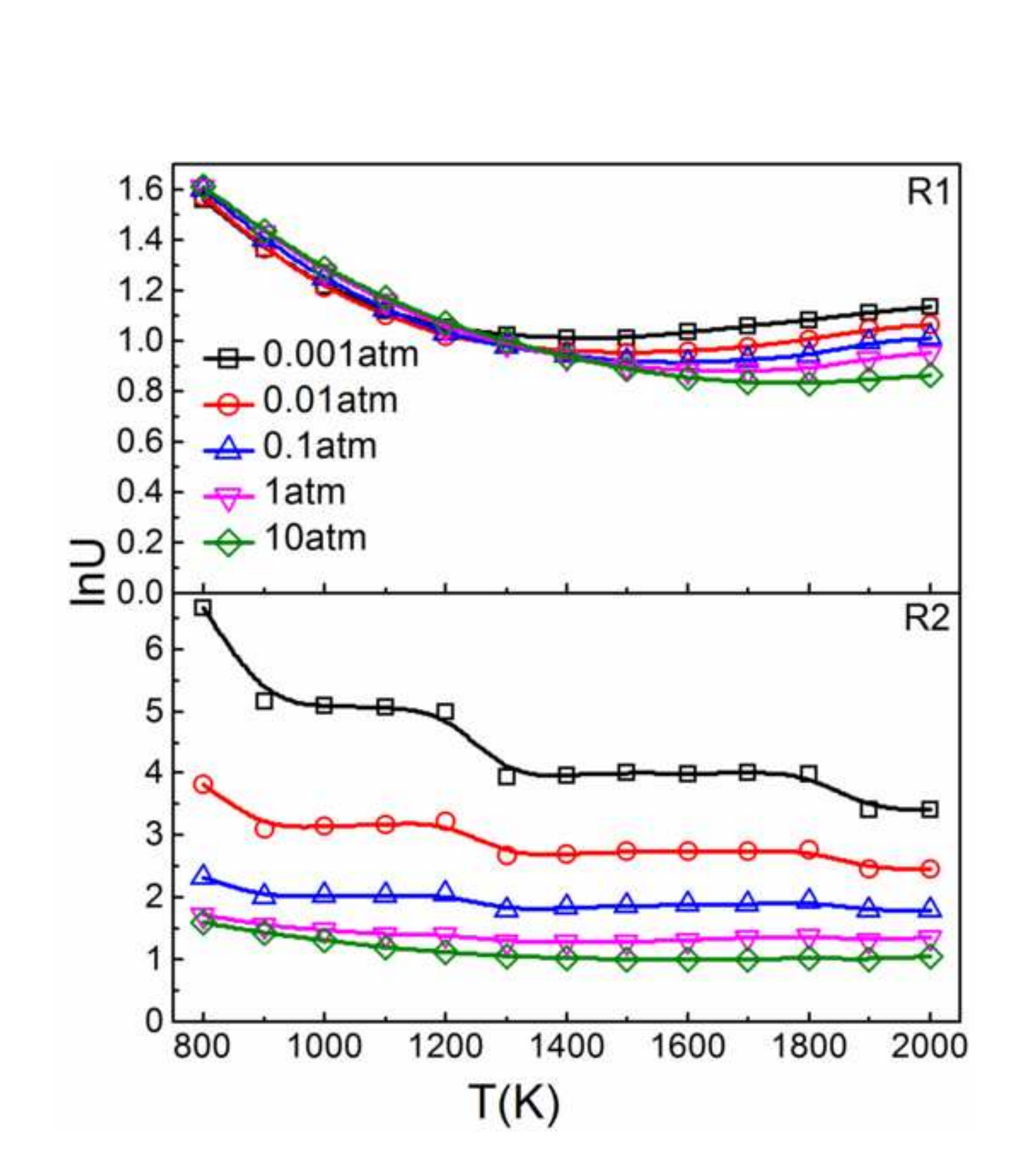


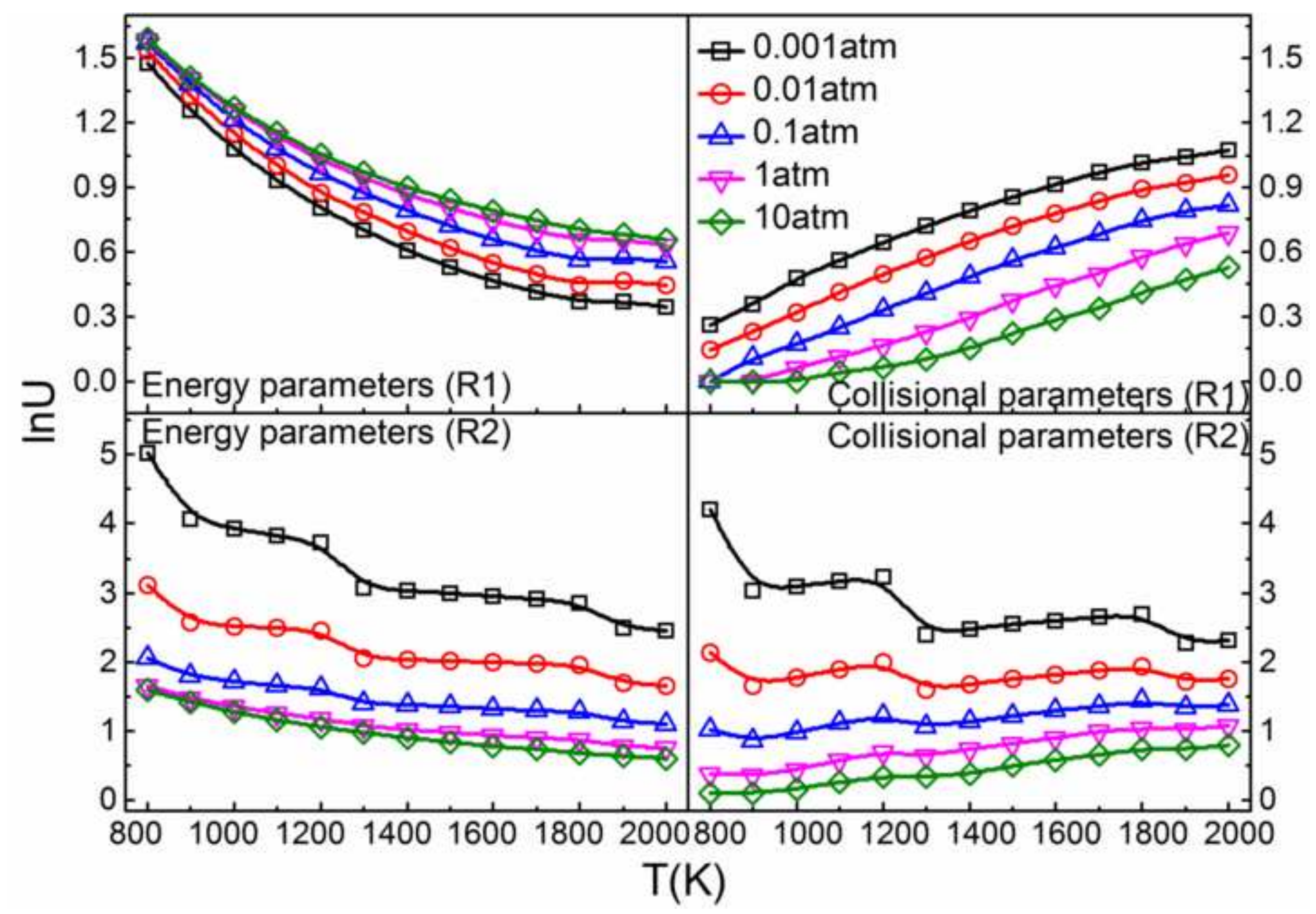

